\title{
Effects of Irradiation Dose on Sperm Production, Insemination, and Male Mating Possible Period in the Sweetpotato Weevil (Coleoptera: Brentidae)
}

\section{Authors: Satoshi Hiroyoshi, Takayuki Mistunaga, Tsuguo Kohama, and Gadi V. P. Reddy}

This is a pre-copyedited, author-produced PDF of an article accepted for publication in Journal of Economic Entomology following peer review. The version of record, see citation below, is available online at: https://dx.doi.org/10.1093/jee/tox363.

Hiroyoshi, Satoshi, Takayuki Mistunaga, Tsuguo Kohama, and Gadi V. P. Reddy. "Effects of Irradiation Dose on Sperm Production, Insemination, and Male Mating Possible Period in the Sweetpotato Weevil (Coleoptera: Brentidae)." Journal of Economic Entomology 111, no. 3 (May 2018): 1151-1156. DOI:10.1093/jee/tox363.

Made available through Montana State University's $\underline{\text { ScholarWorks }}$ scholarworks. montana.edu 


\title{
Effects of Irradiation Dose on Sperm Production, Insemination, and Male Mating Possible Period in the Sweetpotato Weevil (Coleoptera: Brentidae)
}

\author{
Satoshi Hiroyoshi, ${ }^{1,2,3,6}$ Takayuki Mistunaga, ${ }^{4}$ Tsuguo Kohama, ${ }^{1,2}$ and Gadi V. P. Reddy ${ }^{5}$
}

'Okinawa Prefectural Plant Protection Center, 123 Maji, Naha, Okinawa 902-0072, Japan, ${ }^{20 k i n a w a ~ P r e f e c t u r a l ~ A g r i c u l t u r a l ~ R e s e a r c h ~}$ Center, 820 Makabe, Itoman, Okinawa 901-0336, Japan, 37-12-203 Kotobukiso, Nishikawacho, Itoman, Okinawa 901-0304, Japan, ${ }^{4}$ Central Region Agricultural Research Center, National Agriculture and Food Research Organization, 2-1-18 Kannondai, Tsukuba, Ibaraki 305-8602, Japan, ${ }^{5}$ Department of Research Centers, Montana State University, Western Triangle Agrcultural Research Center, 9546 Old Shelby Road, P.0. Box 656, Conrad, MT 59425, and ${ }^{6}$ Corresponding author, e-mail: satoshi_hiroyoshi@yahoo.co.jp

\begin{abstract}
The sterile insect technique (SIT) has been used for the control or eradication of target insect pests. To successfully apply SIT, it is very important to clarify the effect of irradiation on male reproduction in the target pest, because their mating and spermiogenesis abilities affect the success of eradication program. The sweetpotato weevil, Cylas formicarius (Fabricius) (Coleoptera: Brentidae) is a notorious and worldwide pest of sweet potato. We investigated the effect of irradiation at five doses ranging from 0 (control) to $150 \mathrm{~Gy}$ on 9-d-old males. Survival rate of the control (no treatment) remained high from day 10 to 20 of adult life, whereas higher doses of irradiation reduced it, maximally by approximately $70 \%$. Mating rates showed a similar tendency. Radiation dose neither affected sperm production nor sperm transfer at any dose, although spermiogenesis is active during the adult stage. However, radiation dose affected the lifetime total of ejaculated sperm number, likely because of fewer matings by irradiated males. These results suggest that use of a dose of $150 \mathrm{~Gy}$ or higher is appropriate for the final step of eradication of this weevil. At least, lower dose of irradiation may arise the inadequate sterilization, resulting in a failure of eradication program. We conclude that weekly release of sweetpotato weevil sterilized with high dose, achieving complete sterilization, could be useful for eradication program after reducing the population by male annihilation method.
\end{abstract}

Sterile insect technique (SIT) is an environmentally friendly method of insect pest control. SIT is applied as a component of area-wide integrated pest management (AW-IPM) (Klassen 2005). Especially to eradicate the target insect pests, SIT is useful, because this method aims to reduce and finally diminish the population of them. SIT was first used to eradicate the new world screwworm Cochliomyia haminivorax (Coquerel), and then has expanded to tsetse fly, Mediterranean fruit fly, melon fly, or other various insects (Klassen and Curtis 2005). In general, islands surrounded by ocean, like Okinawa Islands in Japan, are relatively easy to use SIT for eradication of target insects, because the migrants distributed in other regions are difficult to enter into Okinawa.

The sweet potato weevil, Cylas formicarius (Fabricius) (Coleoptera: Brentidae), is a serious pest of sweet potato, Ipomoea batatas (L.) in tropical and subtropical areas (Kohama 1990). This weevil feeds on several wild host plants, including I. indica (Burm) Merr., I. pescaprae (L.), I. aquatic Forskl, and
Calystegia soldanella Roem. \& Schult (Kohama and Kuba 2008). This various diet has been a problem for eradication of this weevil, because these host plants support weevil populations often in deep forest, making the control of this species very labor intensive. We had to walk and seek the dangerous places where vipers live in. In Japan, this weevil was first recorded on the subtropical island of Okinawa in 1903, and from there it has spread to neighboring islands (Kohama 1990). At present, these weevils are also found on Amami-Oshima island and its surrounding islands (Kagoshima Prefecture) and on the Ogasawara Islands (Tokyo Metropolis). The spread of plants infested with weevils to uninfested areas is strictly prohibited under the Japanese Plant Protection Law (Kumano et al. 2011). In Okinawa Prefecture, a program for eradicating this pest using a combination of a synthetic female sex pheromone (used for male annihilation and monitoring) and SIT has been underway since 1994 (Yasuda 1995, Moriya 1997, Moriya and Miyatake 2001), and these efforts have recently met with initial success on Kume Island 
(Kohama 2010, D. Haraguchi et al., unpublished data). Although, in general, pupae easier to sterilize than adults (Helinski et al. 2009), we have adopted adult as the target for irradiation due to restraints of our facility and ease of handling (pupation takes place inside the tubers and are relatively difficult to access in quantity). To successfully expand the eradication to other islands, further information about reproduction, especially the mating ability of released sterile males, is needed. The sterilization of this weevil has been studied from the point of view of both SIT (Walker 1966, Ito et al. 1993) and quarantine (Dawes et al. 1987, Sharp 1995, Hallman 2001, Follett 2006). Although the effects of larval and pupal irradiation on survival and spermatogenesis have been well examined in this weevil (Dawes et al. 1987, Sakurai et al. 1994, Sharp 1995, Sakurai et al. 1998), the effects on these parameters of irradiation of the adults are less well understood. Kumano et al. (2008) studied the effects of $200 \mathrm{~Gy}$ of irradiation on survival rate, mating rate, and mating competitiveness, and found that mating ability did not differ between irradiated and control males for the first week after irradiation, after which the mating ability of irradiated males decreased. However, the effects of irradiation on sperm production and insemination were not determined. Here, we examined the effects on male reproductive ability in detail, including adult survival rate, mating rate, sperm production, and sperm transfer of irradiated males, at different levels of irradiation, because this weevil has active spermiogenesis ability in adult stage (Hiroyoshi et al. 2016). Our results supported the usefulness of high irradiation dose (200 Gy) adopted by our facility, resulting in the success of eradication of sweetpotato weevil, although we did not use 200 Gy irradiation in experiments.

\section{Materials and Methods}

\section{Insects}

The colony of C. formicarius used in this study was established with adults originally collected from Yomitan $\left(26^{\circ} 23^{\prime} \mathrm{N}\right.$, $127^{\circ} 44^{\prime} \mathrm{E}$ ), Okinawa Island, in October 1998 and weevils were reared continuously on sweet potatoes at $25 \pm 1^{\circ} \mathrm{C}$ and a $14: 10$ (L:D) h photoperiod until used in experiments in 1999, after approximately 8 to 13 successive generations of laboratory rearing. Approximately total of 500 female and male adult weevils, which were 2 to 6 wk old, were reared in plastic containers (14.5 l). Sweet potatoes (600 g per cage) were provided as food and an oviposition substrate and were changed twice each week. By $5 \mathrm{wk}$ after eggs were laid in sweet potato tubers, most progeny weevils had reached the pupal stage. Pupae were collected by breaking sweet potato tubers open by hand, and undamaged pupae were removed and placed in plastic cups for adult emergence. The day of adult emergence is designated as 0 -d-old. Newly emerged weevils with similar body size were sexed within $2 \mathrm{~d}$ of emergence and held separately in groups of approximately 20 individuals with a piece of sweet potato (about $40 \mathrm{~g}$ ), which was changed twice each week.

\section{Assessment of Mating}

In this weevil, mating takes place at night (Sakuratani et al. 1994). Consequently, to check the mating status of females, weevils were confined as individual pairs in glass Petri dishes (9 cm diameter) during the scotophase. Approximately $16 \mathrm{~h}$ later, females were dissected to check for the presence of sperm in their spermatheca, which was considered an indication of successful mating. Based on earlier studies, we judged that mating without sperm transfer was unlikely to occur in this weevil (Hiroyoshi et al. 2016).

\section{Sperm Counts}

Sperm counts in dissected sterilized males can also be used to evaluate the effectiveness of SIT programs, both in the laboratory weevils and ones collected in the field (Seo et al. 1990). In this study, sperm counts were carried out with established methods (Yamagishi and Tsubaki 1990, Tsubaki and Yamagishi 1991). Males of C. formicarius have a pair of two testes and one seminal vesicle (collectively, the 'testes-seminal vesicle complex' or TSC), with free sperm in both areas. To determine the number of sperm, the male reproductive system was dissected out in a $0.9 \%$ salt solution. The reproductive tract was then placed in a $0.1 \%$ Triton X solution (Kishida Chemical \& Co. Ltd., Osaka, Japan), and the fat bodies carefully removed with tissue paper and forceps (K. Okumura, personal communication). The TSC was then placed in $500 \mu \mathrm{l}$ of deionized water on a glass Petri dish, and the tissues torn into small pieces. The deionized water containing the free sperm was stirred 20 times with forceps to homogenate the sample. Ten microliters of this solution was collected per sample with a microsyringe and spread onto a glass microscope slide and allowed to air-dry. Sperm were counted with a video apparatus (VM-60, Olympus, BR-S925, Victor, and VY-VP20, Hitachi) attached to a microscope, and the sperm count was multiplied by 50 to determine total sperm per weevil.

To count sperm transferred to females during mating, the reproductive organs of females were removed by dissection in $0.9 \%$ salt solution, and the spermatheca isolated and transferred into $100 \mu \mathrm{l}$ of deionized water where the number of sperm was estimated by microscopic examination at $100 x$.

\section{Effect of Radiation Dose on Male Survival, Mating Rate, and Ejaculate Quantity}

To determine the effects of radiation dose on male reproduction, 9-d-old males were irradiated with 0, 50, 70, 100, or 150 Gy units of gamma radiation from a $\mathrm{Co}^{60}$ source. We irradiated many weevils (more than 100) and chose 15 healthy individuals for each of the five treatments, because unhealthy individuals seemed not to live and copulate.

Each irradiated male was then paired with a 20 -d-old or older, nonirradiated sexually mature virgin female, and each pair was confined in a glass Petri dish (diameter $9 \mathrm{~cm}$ ) for one night with a piece of sweet potato tuber $(40 \mathrm{~g})$. For an 11-d observation period (from day 10 to 20 after adult emergence), each pair of weevils was observed daily, and male survival, the presence or absence of mating, and the number of ejaculated sperm per mated male were checked. We replaced females paired with all males daily over the 11-d observation period.

To determine mating rate and number of sperm transferred, all experimental females were dissected after pairing with the test male for one night. If sperm were found in the spermatheca, the male was considered to have mated. Also, the sperm found in the spermatheca for females paired with any particular weevil in all treatments were counted and considered to be the number of sperm ejaculated by the male. After the 11-d observation period, the total ejaculated sperm were summed across all observation days for each male. The number of sperm in the TSC was determined in 20 irradiated (for each dose) or control males, $9,11,17$, or $21 \mathrm{~d}$ after emergence.

\section{Statistical Analysis}

The data on total sperm ejaculated by 9-d-old irradiated males for all radiation doses were subjected to ANOVA followed by Tukey's test for pairwise comparison of the dosage treatments ( $\mathrm{R}$ Development Core Team 2009). ANOVA was also used to compare the number of 
sperm ejaculated per mating and the number of sperm in the TSC in males irradiated at each dose at each designated weevil age, and if necessary, pairwise comparisons using Tukey's HSD test were performed. Survival and mating rates were analyzed with logistic regression to estimate effects of radiation dose. Then, if necessary, pairwise comparisons using a $G$-test weighted by Bonferroni-Holm's correction were performed, first performing the overall test and then doing a pairwise comparison.

\section{Results}

\section{Effect of Radiation Dose on Male Survival, Mating Rate, and Ejaculate Quantity}

We found that the survival of 9-d-old males exposed to different levels of radiation differed significantly, with survival ranging from 70 to $90 \%$ for the irradiated groups by the end of the experiment (11 $\mathrm{d}$ after irradiation) (Fig. 1; Table 1). Pairwise tests indicated survival of the control was $100 \%$ during the observation period, significantly higher than that of males irradiated with 50,100, and 150 Gy. The survival rate of male adults irradiated with $150 \mathrm{~Gy}$ was significantly lower than that of all other treatment groups except for the 100 Gy group.

We also found significant differences in male mating rates with radiation dose (Fig. 2) (as well as for weevil age and the interaction of radiation dose and postirradiation age) (Table 2). At the highest dose, by the end of the experiment, only $13 \%$ of males mated daily, compared to $80 \%$ of control males (Fig. 2). There were significant differences in the mating rates between the control and 50, 70, 100, or 150 Gy treatments. Mating rates of the control remained high throughout the observation period, while that of irradiated males began to decrease several days after irradiation.

We found few significant differences in the number of sperm produced in TSCs by control versus irradiated individuals (ANOVA: age $13 \mathrm{~d}, \mathrm{df}=4, F=1.099, P=0.361$; age $17 \mathrm{~d}, \mathrm{df}=4, F=3.714$, $P=0.007$; age $21 \mathrm{~d}, \mathrm{df}=4, F=2.143, P=0.081$ ) (Table 3 ). These results suggest that radiation dose did not affect sperm production and that a reduction of mating rates observed in irradiated males over the course of the observation period was not due to the depletion of sperm in the TSCs. In fact, we observed that the seminal vesicle of males surviving beyond the observation period often had relatively large numbers of sperm remaining.

The number of sperm ejaculated per mating ranged between 500 and 1,000 (Table 4). There were no significant differences except for day 16 between male adults irradiated with different doses and the control (ANOVA; $\mathrm{df}=4, F=2.396, P=0.06$ ) (Table 4). These

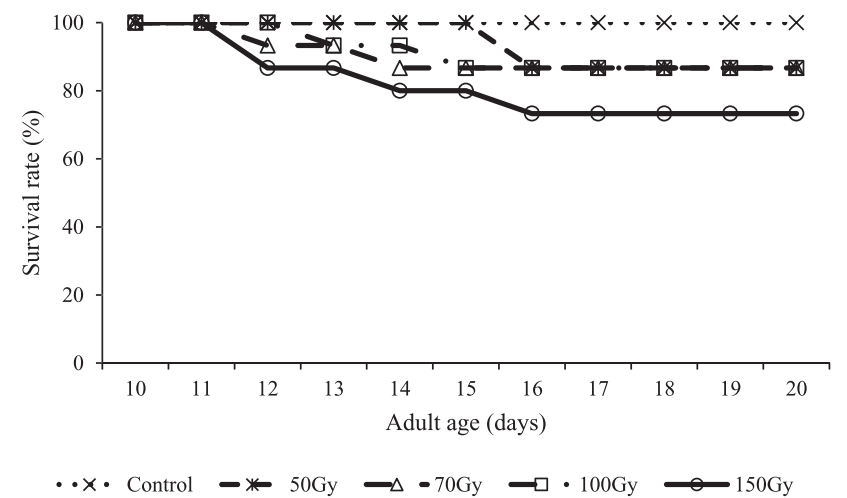

Fig. 1. Survival rate of $C$. formicarius males irradiated with different doses at 9-d-old from 10 to $20 \mathrm{~d}$ of adult life. results suggest that the number of sperm ejaculated per mating did not differ between the control and irradiated individuals. There were, however, significant differences between 150-Gy-irradiated males and control males (ANOVA; $\mathrm{df}=4, F=6.441, P=0.00018$ ) in the total number ejaculated sperm number during the observation period (Table 5). Total ejaculated sperm in the former was less than half than that in the latter.

\section{Discussion}

Our results suggest that when males of $C$. formicarius are exposed to various doses of irradiation at 9-d of adult weevil life, higher radiation dose corresponds with lower survival rate (Fig. 1) and mating rate (Fig. 2), especially late in the observation period (from 10 to

Table 1. The results of logistic regression analysis on the effects of irradiation dose and age on the survival rate of $C$. formicarious

\begin{tabular}{|c|c|c|c|}
\hline Factor & $\mathrm{df}$ & Likelihood rate $\chi^{2}$ & $P$-value \\
\hline \multicolumn{4}{|l|}{ Overall test } \\
\hline Irradiation dose & 4 & 47.75376 & $<0.001^{*}$ \\
\hline Age & 1 & $1.30572 \mathrm{E}-06$ & 0.9991 \\
\hline Irradiation dose $\times$ age & 4 & 3.01672 & 0.555 \\
\hline \multicolumn{4}{|l|}{ Pairwised test } \\
\hline \multicolumn{4}{|l|}{ Control vs 50 Gy } \\
\hline Irradiation dose & 1 & 7.087747 & $<0.001^{*}$ \\
\hline \multicolumn{4}{|l|}{ Control vs $70 \mathrm{~Gy}$} \\
\hline Irradiation dose & 1 & 11.498175 & $<0.001^{*}$ \\
\hline \multicolumn{4}{|l|}{ Control vs $100 \mathrm{~Gy}$} \\
\hline Irradiation dose & 1 & 10.014289 & $<0.001^{*}$ \\
\hline \multicolumn{4}{|l|}{ Control vs $150 \mathrm{~Gy}$} \\
\hline Irradiation dose & 1 & 23.902148 & $<0.001^{*}$ \\
\hline \multicolumn{4}{|l|}{$50 \mathrm{~Gy}$ vs $70 \mathrm{~Gy}$} \\
\hline Irradiation dose & 1 & 0.75780156 & 0.2183 \\
\hline \multicolumn{4}{|l|}{50 Gy vs 100 Gy } \\
\hline Irradiation dose & 1 & 0.36103849 & 0.3955 \\
\hline \multicolumn{4}{|l|}{50 Gy vs 150 Gy } \\
\hline Irradiation dose & 1 & 6.5005542 & $<0.001^{*}$ \\
\hline \multicolumn{4}{|l|}{70 Gy vs $100 \mathrm{~Gy}$} \\
\hline Irradiation dose & 1 & 0.07388285 & 0.7016 \\
\hline \multicolumn{4}{|l|}{70 Gy vs $150 \mathrm{~Gy}$} \\
\hline Irradiation dose & 1 & 3.1725291 & 0.0118 \\
\hline \multicolumn{4}{|l|}{100 Gy vs 150 Gy } \\
\hline Irradiation dose & 1 & 4.1884226 & $0.0038^{*}$ \\
\hline
\end{tabular}

For pairwised tests, asterisk indicates the significant difference $(P<0.05 / 10)$ with a Bonferroni correction.

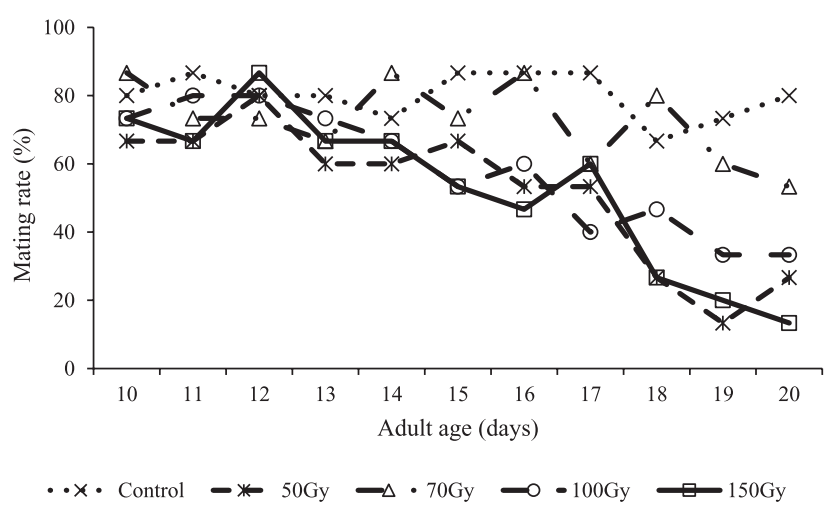

Fig. 2. Mating rate of $C$. formicarius males irradiated with different doses at 9-d-old from 10 to $20 \mathrm{~d}$ of adult life. 
Table 2. The results of logistic regression analysis on the effects of irradiation dose and age on the mating rate of $C$. formicarious

\begin{tabular}{|c|c|c|c|}
\hline Factor & $\mathrm{df}$ & Likelihood rate $\chi^{2}$ & $P$-value \\
\hline \multicolumn{4}{|l|}{ Overall test } \\
\hline Irradiation dose & 4 & 28.9343879 & $<0.001 *$ \\
\hline Age & 1 & 67.661897 & $<0.001 *$ \\
\hline Irradiation dose $\times$ age & 4 & 23.3774311 & $<0.001^{*}$ \\
\hline \multicolumn{4}{|l|}{ Pairwised test } \\
\hline \multicolumn{4}{|l|}{ Control vs $50 \mathrm{~Gy}$} \\
\hline Irradiation dose & 1 & 21.5791297 & $<0.001 *$ \\
\hline Age & 1 & 8.4746572 & $0.0036^{*}$ \\
\hline Irradiation dose $\times$ age & 1 & 3.88380552 & 0.0488 \\
\hline \multicolumn{4}{|l|}{ Control vs $70 \mathrm{~Gy}$} \\
\hline Irradiation dose & 1 & 0.01369363 & 0.9103 \\
\hline Age & 1 & 1.11715352 & 0.2905 \\
\hline Irradiation dose $\times$ age & 1 & 0.04327456 & 0.8352 \\
\hline \multicolumn{4}{|l|}{ Control vs $100 \mathrm{~Gy}$} \\
\hline Irradiation dose & 1 & 10.3830033 & $0.0013^{*}$ \\
\hline Age & 1 & 7.18720473 & 0.0073 \\
\hline Irradiation dose $\times$ age & 1 & 3.06638266 & 0.0799 \\
\hline \multicolumn{4}{|l|}{ Control vs 150 Gy } \\
\hline Irradiation dose & 1 & 4.63126549 & 0.0314 \\
\hline Age & 1 & 11.5797218 & $0.0007^{*}$ \\
\hline Irradiation dose $\times$ age & 1 & 6.37172983 & 0.0166 \\
\hline \multicolumn{4}{|l|}{$50 \mathrm{~Gy}$ vs $70 \mathrm{~Gy}$} \\
\hline Irradiation dose & 1 & 20.9266947 & $<0.001 *$ \\
\hline Age & 1 & 9.28595904 & $0.0023 *$ \\
\hline Irradiation dose $\times$ age & 1 & 2.86329567 & 0.0906 \\
\hline \multicolumn{4}{|l|}{50 Gy vs 100 Gy } \\
\hline Irradiation dose & 1 & 1.86590921 & 0.1719 \\
\hline Age & 1 & 25.4210864 & $<0.001 *$ \\
\hline Irradiation dose $\times$ age & 1 & 0.04672443 & 0.8289 \\
\hline \multicolumn{4}{|l|}{50 Gy vs 150 Gy } \\
\hline Irradiation dose & 1 & 4.34839387 & 0.037 \\
\hline Age & 1 & 31.9627781 & $<0.001 *$ \\
\hline Irradiation dose $\times$ age & 1 & 0.54308745 & 0.4512 \\
\hline \multicolumn{4}{|l|}{$70 \mathrm{~Gy}$ vs $100 \mathrm{~Gy}$} \\
\hline Irradiation dose & 1 & 10.2245422 & $0.0014^{*}$ \\
\hline Age & 1 & 7.97229296 & $0.0047^{*}$ \\
\hline Irradiation dose $\times$ age & 1 & 2.19571731 & 0.1384 \\
\hline \multicolumn{4}{|l|}{70 Gy vs 150 Gy } \\
\hline Irradiation dose & 1 & 4.55028833 & 0.0329 \\
\hline Age & 1 & 12.4090898 & $<0.001^{*}$ \\
\hline Irradiation dose $\times$ age & 1 & 5.07704599 & 0.0242 \\
\hline \multicolumn{4}{|l|}{100 Gy vs $150 \mathrm{~Gy}$} \\
\hline Irradiation dose & 1 & 0.65581282 & 0.418 \\
\hline Age & 1 & 29.0677221 & $<0.001 *$ \\
\hline Irradiation dose $\times$ age & 1 & 0.86286989 & 0.3529 \\
\hline
\end{tabular}

For pairwised tests, asterisk indicates the significant difference $(P<0.05 / 10)$ with a Bonferroni correction.
$20 \mathrm{~d}$ of adult life). This appears to be caused by damage to the midgut reducing behavioral activity such as feeding. Thus, the possible mating period of males irradiated with a high dose is brief, which strongly suggests that frequent (e.g., weekly) release of irradiated weevils may be necessary for the success of an SIT program against this pest. On the other hand, neither sperm production nor the number of sperm ejaculated per mating were affected by radiation dose in this study (Tables 3 and 4), although the total number of sperm ejaculated in males irradiated with a dose of $150 \mathrm{~Gy}$ was much lower than in the control (Table 5). This appears to be caused by no mating or infrequent mating late in the observation period. However, in another study, irradiated males showed a decline in the number of sperm produced and transferred, in the boll weevil, Anthonomus grandis (Grandis) (Nilakhe and Earle 1976a,b). This implies that irradiation of 9-d-old weevil adults did not affect spermiogenesis of C. formicarius, except for damage to the chromosome of sperm.

Sterility effects can vary with species; for instance, sperm of the potato tuber moth, Phthorimaea opereculella (Zeller), for adults irradiated with $150 \mathrm{~Gy}$, recovered their viability after 10 successive matings (Makee and Saour 1999). Higher doses of irradiation in this study apparently affected the nutritional condition of C. formicarius weevils. Thus, this treatment shortened not only the survival period but also the possible mating period as shown in this study and in Kumano et al. (2008). Thus, weevils irradiated with a high dose and then released into the field could only copulate for a short term.

As a high dose of irradiation shortens the survival and possible mating period in C. formicarius (Kumano et al. 2008, 2010), frequent release (weekly) of weevils may be necessary for eradication, as mentioned above. Both dose and insect stage or age at irradiation need to be considered and perhaps altered, depending on the stage of an eradication program, choosing either partial sterility (and better mating success) or complete sterilization (and lower mating success) at different stages. In cases where eradication rather than the control of target pest is required, complete sterilization is desirable.

In C. formicarius, various doses of irradiation in 9-d-old adult males did not affect sperm production and sperm transfer compared with the controls (Tables 3 and 4). However, in the fig moth, Ephestia cautella (Walker), gamma radiation negatively affected spermiogenesis (Shawket et al. 1989). In irradiated boll weevils, two-thirds of the sperm transferred into females were forced out of the spermathecae (Nilakhe 1977). We found a similar phenomenon in C. formicarius. Males of this weevil transfer excess sperm to the females, and sperm unable to enter the spermatheca are expelled from the female copulatory tracts (Hiroyoshi et al. 2016). As this weevil continues to produce sperm through adulthood, they are able to supply a surplus of sperm even after mating several times (Hiroyoshi et al. 2016).

Lower radiation may not adequately reduce fertility, reducing the efficacy of an eradication program (Collins and Taylor 2011).

Table 3. Change of the number of sperm in a pair of testes and seminal vesicles of $C$. formicarius males irradiated with different dose at 9-d-old during $9,13,17$, or $21 \mathrm{~d}$ of adult life

No. of sperm in the testes and seminal vesicles

Adult age (days)

\begin{tabular}{lcccr}
\cline { 2 - 4 } Dose & 9 & 13 & 17 & 21 \\
\hline Normal & $12,005 \pm 5,861$ & $27,492.5 \pm 9,281^{\mathrm{a}}$ & $42,045 \pm 11,405^{\mathrm{ab}}$ & $57,723 \pm 16,593^{\mathrm{a}}$ \\
50 Gy & & $26,675 \pm 15,832^{\mathrm{a}}$ & $38,610 \pm 15,940^{\mathrm{ab}}$ & - \\
70 Gy & & $26,745 \pm 8,751^{\mathrm{a}}$ & $36,985 \pm 13,867^{\mathrm{b}}$ & $60,638 \pm 10,891^{\mathrm{a}}$ \\
$100 \mathrm{~Gy}$ & $30,060 \pm 8,654^{\mathrm{a}}$ & $50,205 \pm 15,695^{\mathrm{a}}$ & $48,592 \pm 17,396^{\mathrm{a}}$ \\
150 Gy & & $42,090 \pm 9,989^{\mathrm{a}}$ & $49,638 \pm 13,943^{\mathrm{a}}$ & $60,665 \pm 13,260^{\mathrm{a}}$ \\
\hline
\end{tabular}

Different letters indicate significant differences at each adult age. 
Table 4. The number of sperm ejaculated per mating by $C$. formicarius males irradiated with different doses at 9 -d-old from 10 to $20 \mathrm{~d}$ of adult life

\begin{tabular}{|c|c|c|c|c|c|}
\hline \multirow[b]{3}{*}{ Observation period (day) } & \multicolumn{5}{|c|}{ No. of ejaculated sperm } \\
\hline & \multicolumn{5}{|c|}{ Irradiation of dose (Gy) } \\
\hline & 0 & 50 & 70 & 100 & 150 \\
\hline 10 & $990.7 \pm 1,147.9^{a}$ & $740.8 \pm 889.3^{a}$ & $1,280.4 \pm 1,230.5^{a}$ & $1,003 \cdot 3 \pm 1,139.7^{a}$ & $491.2 \pm 761.1^{a}$ \\
\hline 11 & $690.3 \pm 923.2^{a}$ & $585.6 \pm 802.4^{a}$ & $638.4 \pm 756.1^{\mathrm{a}}$ & $1,113.3 \pm 1,525.7^{a}$ & $445.0 \pm 652.6^{a}$ \\
\hline 12 & $667.1 \pm 568.8^{\mathrm{a}}$ & $580.1 \pm 902.2^{\mathrm{a}}$ & $748.2 \pm 651.8^{\mathrm{a}}$ & $1,223.7 \pm 1,075.5^{\mathrm{a}}$ & $568.1 \pm 535.2^{\mathrm{a}}$ \\
\hline 13 & $757.2 \pm 620.9^{a}$ & $704.6 \pm 865.7^{a}$ & $924.7 \pm 1,152.4^{a}$ & $913.7 \pm 1,575.9^{a}$ & $441.2 \pm 733.0^{\mathrm{a}}$ \\
\hline 14 & $828.7 \pm 1,009.5^{\mathrm{a}}$ & $959.7 \pm 1,328.9^{a}$ & $817.7 \pm 667.9^{a}$ & $711.9 \pm 1,097.8^{\mathrm{a}}$ & $261.0 \pm 258.7^{a}$ \\
\hline 15 & $1,012 \pm 1,036.7^{\mathrm{a}}$ & $586.1 \pm 922.9^{a}$ & $634.4 \pm 656.2^{\mathrm{a}}$ & $707.8 \pm 936.8^{\mathrm{a}}$ & $519.0 \pm 634.5^{\mathrm{a}}$ \\
\hline 16 & $588.9 \pm 658.3^{\mathrm{ab}}$ & $779.3 \pm 912.4^{\mathrm{ab}}$ & $1,195 \pm 847.2^{\mathrm{a}}$ & $355.6 \pm 379.6^{b}$ & $596.5 \pm 744.7^{\mathrm{ab}}$ \\
\hline 17 & $1,290.3 \pm 1,469.8^{a}$ & $975.2 \pm 1,075.3^{a}$ & $770.2 \pm 906.7^{a}$ & $654.9 \pm 994.0^{\mathrm{a}}$ & $1,126.5 \pm 909.2^{a}$ \\
\hline 18 & $710.0 \pm 904.7^{a}$ & $514.2 \pm 989.7^{a}$ & $1,077.9 \pm 1,437.2^{\mathrm{a}}$ & $778.5 \pm 1,114.1^{a}$ & $195.8 \pm 379.7^{a}$ \\
\hline 19 & $646.5 \pm 863.0^{\mathrm{ab}}$ & $157.1 \pm 495.6^{a}$ & $828.3 \pm 631.3^{\mathrm{b}}$ & $236.0 \pm 513.3^{\mathrm{ab}}$ & $111.5 \pm 246.7^{a}$ \\
\hline 20 & $823.6 \pm 784.1^{\mathrm{a}}$ & $143.8 \pm 320.9^{a}$ & $1,000.8 \pm 1,507.9^{a}$ & $380.8 \pm 681.5^{a}$ & $287.1 \pm 897.1^{\mathrm{a}}$ \\
\hline
\end{tabular}

Different letters among treatment indicate significant differences at each adult age.

Table 5. Differences of total number of sperm ejaculated by irradiation doses

\begin{tabular}{lcc}
\hline & \multirow{2}{*}{$\begin{array}{c}\text { No. of } \\
\text { animals used }\end{array}$} & \begin{tabular}{c} 
Total number of sperm ejaculated \\
\cline { 3 - 3 } Irradiation dose
\end{tabular} \\
\hline CT & 15 & Average $\pm S D$ \\
50 Gy & 15 & $9,005.3 \pm 4,907.2^{\mathrm{a}}$ \\
$70 \mathrm{~Gy}$ & 15 & $6,383.7 \pm 4,837.41^{\mathrm{ab}}$ \\
$100 \mathrm{~Gy}$ & 15 & $8,967.3 \pm 4,419.0^{\mathrm{a}}$ \\
$150 \mathrm{~Gy}$ & 15 & $7,556.1 \pm 5,862.6^{\mathrm{ab}}$ \\
\hline
\end{tabular}

Different letters indicate significant differences.

The optimal dose for an SIT program depends on the level of sterility induced and the mating competitiveness of the resulting irradiated males. A low dose of irradiation may give a rise to insufficiently sterilized males, whereas a high dose of irradiation may undermine the male's ability to compete with wild males, resulting in reduction of the overall impact of the release (Helinski et al. 2006). Furthermore, incomplete sterilization is often followed by a recovery of fertility overtime. Although we did not examine the mating competitiveness, fertility, and fecundity of irradiated C. formicarius males and females, the present study indicated that radiation dose did not affect sperm production and ejaculated sperm number per day, but did reduce total ejaculated sperm number and mating behavior. In another study by Kumano et al. (2010), irradiated males of C. formicarius treated with 125 and 150 Gy had low fertility. Although irradiation dose has a significant effect on the mating behavior in both Anastrepha ludens Loew (Orozco-Dávila et al. 2015), as it did with our study weevil, 200 Gy dose of irradiation appears to be the dose to achieve complete sterility in C.formicarius (Kuriwada 2013).

Stage or age also affects survival, mating competitiveness, spermatogenesis, and fecundity (Abila et al. 2003, de Beer et al. 2015). We will report the effects of stage or age on male reproduction of $C$. formicarius in the near future.

\section{Acknowledgments}

We would like to thank Y. Nakamoto and Y. Sokei for irradiating the insects. We also thank the staff of Ryukyu Sankei Co. Ltd. and Dr. S. Moriya,
Dr. K. Tateishi, and Mr. K. Takashino for their help. Thanks are also due to Dr. J. Koyama for his invaluable advice. Two anonymous reviewers improved the manuscript.

\section{References Cited}

Abila, P. P., M. Kiendrebeogo, G. N. Mutika, A. G. Parker, and A. S. Robinson. 2003. The effect of age on the mating competitiveness of male Glossina fuscipes fuscipes and G. palpalis palpalis. J. Insect Sci. 3: 13.

Collins, S. R., and P. W. Taylor. 2011. Fecundity, fertility and reproductive recovery of irradiated Queensland fruit fly Bactrocera tryoni. Physiol. Entomol. 36: 247-252.

Dawes, M. A., R. S. Saini, M. A. Mullen, J. H. Brower, and P. A. Loretan. 1987. Sensitivity of sweetpotato weevil (Coleoptera: Curclionidae) to gamma radiation. J. Econ. Entomol. 80: 142-146.

de Beer, C. J., G. J. Venter, and M. J. Vreysen. 2015. Determination of the optimal mating age of colonised Glossina brevipalpis and Glossina austeni using walk-in field cages in South Africa. Parasit. Vectors. 8: 467.

Follett, P. A. 2006. Irradiation as a methyl bromide alternative for postharvest control of Omphisa anastomosalis (Lepidoptera: Pyralidae) and Euscepes postfasciatus and Cylas formicarius elegantulus (Coleoptera: Curculionidae) to gamma radiation. J. Econ. Entomol. 99: 32-37.

Hallman, G. J. 2001. Ionizing irradiation quarantine treatment against treatment sweetpotato weevil (Coleoptera: Curculionidae). Fla. Entomol. 84: 415-417.

Helinski, M. E., A. G. Parker, and B. G. Knols. 2006. Radiation-induced sterility for pupal and adult stages of the malaria mosquito Anopheles arabiensis. Malar. J. 5: 41.

Helinski, M. E., A. G. Parker, and B. G. Knols. 2009. Radiation biology of mosquitoes. Malar. J. 8(Suppl 2): S6.

Hiroyoshi, S., T. Kohama, and G. V. P. Reddy. 2016. Age-related sperm production, transfer, and storage in the sweet potato weevil, Cylas formicarius (Fabricius) (Coleoptera: Curculionidae). J. Insect Behav. 29: 689-707.

Ito, S., M. Higashi, T. Hoshida, T. Nagayama, S. Kameda, T. Tokunaga, M. Oshikawa, and C. Maeda. 1993. Gamma irradiation of sweet potato weevil pupae, Cylas formicarius (Fabricuis) (Coleoptera: Brentidae): effects of irradiation at low dose on fecundity, sexual competitiveness, longevity and malformation after adult eclosion [in Japanese with English abstract]. Res. Bull. Plant Prot. Ser. Japan 29: 45-48.

Kohama, T. 1990. Invasion and colonization of the sweetpotato weevils in Okinawa and current problems for their control. Shokubutsu-boeki. 44: 115-117 (in Japanese).

Kohama, T. 2010. Progress in the programme to eradicate sweet-potato weevils using a combination of male annihilation by sex-pheromone and sterile insect releases on Kume Island, Okinawa, Japan. Insect Pest Cont. Newsletter. 74: 32-33. 
Kohama, T., and H. Kuba. 2008. The eradication program of the sweetpotato weevil Cylas formicarius (Fabricius) (Coleoptera: Brentidae), using both of sex-pheromone and sterile insect technique in Kume Island, pp. 277-316. In $\mathrm{Y}$. Ito (ed.), Sterile insect technique: eradication technique for invasive species. Kaiyusha, Tokyo, Japan (in Japanese).

Klassen, W. 2005. Area-wide intergrated pest management and the sterile insect technique, pp. 39-68. In V. A. Dyck, J. Hendrichs, and A. S. Robinson (eds.), Sterile insect technique: principles and practice in areawide integrated pest management. IAEA, Springer, The Netherlands.

Klassen, W., and C. F. Curtis. 2005. History of the Sterile Insect Technique, pp. 39-68. In V. A. Dyck, J. Hendrichs, and A. S. Robinson (eds.), Sterile insect technique: principles and practice in area-wide integrated pest management. IAEA, Springer, The Netherlands.

Kumano, N., D. Haraguchi, and T. Kohama. 2008. Effect of irradiation on mating ability in the male sweetpotato weevil (Coleoptera: Curculionidae). J. Econ. Entomol. 101: 1198-1203.

Kumano, N., T. Kuriwada, K. Shiromoto, D. Haraguchi, and T. Kohama. 2010. Assessment of effect of partial sterility on mating performance in sweetpotato weevil (Coleoptera: Curculionidae). J. Econ. Entomol. 103: 2034-2041.

Kumano, N., T. Kuriwada, K. Shiromoto, D. Haraguchi, and T. Kohama. 2011. Prolongation of the effective copulation period by fractionated-dose irradiation in the sweet potato weevil, Cylas formicarius. Entomol. Exp. Appl. 141: 129-137.

Kuriwada, T. 2013. Recent advances in the study for eradication projects of the sweet potato weevil. Jap. J. Appl. Entomol. Zool. 57: 1-10 (in Japanese).

Makee, H., and G. Saour. 1999. Nonrecovery of fertility in partially sterile male Phthorimaea operculella (Lepidoptera: Gelechiidae). J. Econ. Entomol. 92: 516-520.

Moriya, S. 1997. Is it possible to eradicate the two weevil pests of sweet potato, Cyalas formicarius and Euscepes postfasciatus from Japan? Bull Okinawa Agri. Exp. Stat. 18: 19-27.

Moriya, S., and T. Miyatake. 2001. Eradication programs of two sweet potato pests, Cylas formicarius and Euscepes postfasciatus, in Japan with special reference to their dispersal ability. JARQ. 35: 227-234

Nilakhe, S. S. 1977. Boll weevils: sperm transfer by sterile vs normal males; fecundity and the use of sperm by females. Ann. Entomol. Soc. Amer. 70: 929-932.

Nilakhe, S. S., and N. W. Earle. 1976a. Mating frequency of normal vs. sterile male boll weevils in the laboratory. J. Econ. Entomol. 69: 459-461.
Nilakhe, S. S., and N. W. Earle. 1976b. Sperm production in normal vs. sterile boll weevils. J. Econ. Entomol. 69: 609-613.

Orozco-Dávila, D., M. d. e. L. Adriano-Anaya, L. Quintero-Fong, and M. Salvador-Figueroa. 2015. Sterility and sexual competitiveness of Tapachula-7 Anastrepha ludens males irradiated at different doses. PLoS One. 10: e0135759.

R Development Core Team. 2009. R: a language and environment for statistical computing. R Foundation for Statistical Computing, Vienna, Austria.

Sakurai, H., Y. Tsuchiyama, M. Izumi, and T. Yamaguchi. 1998. Ultrastructural studies on the mechanism of sterilization by gamma-radiation in the sweetpotato weevil, Cylas formicarius. Res. Bull. Fac. Agri., Gifu Univ. 63: 31-36 (in Japanese with English summary).

Sakurai, H., H. Watanabe, T. Sugimoto, Y. Sakuratani, O. Setoguchi, and K. Kawazoe. 1994. Effects of gamma-radiation on the gametogenesis in the sweetpotato weevil, Cylas formicarius. Res. Bull. Fac. Agri., Gifu Univ. 59: 11-20 (in Japanese with English summary).

Sakuratani, Y., T. Sugimoto, O. Setokuchi, T. Kamikado, K. Kiritani, and T. Okada. 1994. Diurnal changes in micro-habitat usage and behavior of Cylas formicarius ( $\mathrm{F}_{\text {ABRicius }}$ ) (Coleoptera: Curculionidae) adults. Appl. Entomol. Zool. 29: 307-315.

Seo, S. T., R. I. Vargas, J. E. W. Gilmore, R. S. Kurashima, and M. S. Fujimoto 1990. Sperm transfer in normal and gamma-irradiated, laboratory-reared Mediterranean fruit flies (Diptera: Tephritidae). J. Econ. Entomol. 83: 1949-1953.

Sharp, J. L. 1995. Mortality of sweetpotato weevil (Coleoptera: Apionidae) stages exposed to gamma irradiation. J. Econ. Entomol. 88: 688-692.

Shawket M. A., A. A. Al-Taweel, and Ha Al-Al. 1989. Cytological action of gamma rays on spermatogenesis in Ephesita cautella Walker (Lepidoptera: Pyralidae). The Nucleus 32: 83-85.

Tsubaki, Y., and M. Yamagishi. 1991. "Longevity" of sperm within the female of the melon fly, Dacus cucurbitae (Diptera: Tephritidae), and its relevance to sperm competition. J. Insect Behav. 4: 243-250

Walker, J. R. 1966. Reproductive potential of the sweetpotato weevil after exposure to ionizing radiations. J. Econ. Entomol. 59: 1206-1208.

Yamagishi, M., and Y. Tsubaki. 1990. Copulation duration and sperm transfer in the melon fly, Dacus cucurbitae $\mathrm{C}_{\text {oquiletet }}$ (Diptera: Tepharitidae). Appl. Entomol. Zool. 25: 517-519.

Yasuda, K. 1995. Mass trapping of the sweet potato weevil Cylas formicarius (Fabricius) (Coleoptera: Brentidae) with a synthetic sex pheromone. Appl. Entomol. Zool. 30: 31-36. 